\title{
Development of a real-time PCR assay for the identification of Gyrodactylus parasites infecting salmonids in northern Europe
}

\author{
Catherine M. Collins ${ }^{1, *}$, Rose Kerr ${ }^{2}$, Rebecca McIntosh ${ }^{1}$, Mike Snow ${ }^{1}$ \\ ${ }^{1}$ Marine Scotland, Marine Laboratory, PO Box 101, Victoria Rd, Aberdeen AB11 9DB, UK \\ ${ }^{2}$ CEFAS Laboratory, The Nothe, Barrack Rd, Dorset DT4 8UB, UK
}

\begin{abstract}
Gyrodactylus salaris is a monogenean freshwater parasite that causes high mortality in wild Atlantic salmon, and a number of countries employ monitoring programmes for its presence. A TaqMan®-MGB (minor groove binding) probe real-time multiplex assay targeting the internal transcribed spacer ribosomal DNA (ITS rDNA) was developed to simultaneously identify G. salaris/ G. thymalli and 2 other commonly occurring Gyrodactylus species infecting salmonids in northern Europe: G. derjavinoides and G. truttae. In addition, a Gyrodactylus genus-level assay was developed to assess parasite DNA quality. The species-specific real-time PCR method correctly identified target species from a wide geographical range and from a number of salmonid hosts. It did not amplify G. lucii or G. teuchis. These species were successfully amplified using the Gyrodactylus genus real-time assay. The species-specific real-time assay proved to be significantly faster than the currently employed molecular screening method of ITS rDNA PCR amplification followed by restriction fragment length polymorphism analyses (RFLP). However, as with ITS RFLP, the real-time method did not distinguish between $G$. salaris and the non-pathogenic G. thymalli, its principle advantage being a significant reduction in time to achieve an initial diagnostic screen before the employment of more in-depth analyses for those specimens giving a positive G. salaris/G. thymalli real-time result.
\end{abstract}

KEY WORDS: Gyrodactylus salaris · Diagnostic $\cdot$ TaqMan-MGB real-time PCR

\section{INTRODUCTION}

Gyrodactylus salaris is a monogenean ectoparasite of freshwater salmonids. To date it has only been reported within Europe (Malmberg 1993). It is highly virulent towards Atlantic salmon Salmo salar L., eastern Atlantic salmon strains. Its direct lifecycle (Jansen \& Bakke 1991, Cable \& Harris 2002) and the apparent inability of Atlantic salmon to control G. salaris infection results in population explosions of the parasite on the host. Since its introduction to Norway in the late 1970s, G. salaris has caused the decimation of a number of important salmon rivers (Johnsen et al. 1999, Peeler et al. 2006).

Gyrodactylus salaris is included on list III of the Office International des Épizooties (OIE) as a notifiable pathogen. In Europe it is not listed under Council Directive 2006/88/EC (Council of the European Union 2006), but is covered by some countries under 'addi- tional guarantees' set out in Commission Decision 2004/453/EC. Even though there is no obligation to monitor for the presence of $G$. salaris in areas declared free of the parasite, many countries still maintain monitoring programmes with the aim of an early warning of its introduction so that management and eradication programmes can be implemented and damage to wild salmon populations minimised.

The classical method of Gyrodactylus species identification is through morphological examination of the opisthaptor (attachment organ) hard parts. Differences between some species can be quite small and thus a high level of expertise is required. PCR amplification of the internal transcribed spacer ribosomal DNA (ITS rDNA) followed by analysis of restriction fragment length polymorphism (RFLP) patterns (Cunningham 1997) has been used for a number of years in monitoring programmes for G. salaris in Scotland. 
The taxonomy of Gyrodactylus salaris is complicated by the description of $G$. thymalli, a parasite of grayling Thymallus thymallus, which is not pathogenic to Atlantic salmon (Bakke et al. 2002, Sterud et al. 2002). G. salaris is morphologically very similar to G. thymalli. G. thymalli and most strains of $G$. salaris also share identical ITS rDNA sequence, so that ITS RFLP cannot be used to differentiate between them. Some authors (Hansen et al. 2006, Kuusela et al. 2007) consider G. thymalli synonymous with $G$. salaris, although this has not been formally accepted. In addition, gyrodactylids identified as G. salaris which do not display pathogenicity towards Atlantic salmon have been found on charr and rainbow trout (Lindenstrøm et al. 2003, Jørgensen et al. 2007, Olstad et al. 2007, Robertsen et al. 2007). These G. salaris strains differ in 1 to 3 nucleotide positions in their ITS rDNA compared to pathogenic forms. Phylogenetic analysis of mitochondrial cytochrome c oxidase subunit I (COI) sequences has been used to discriminate between $G$. thymalli and G. salaris populations (Hansen et al. 2003, Meinilä et al. 2004). However, no definitive nucleotide difference in the COI region exists which identifies all $G$. salaris or all G. thymalli only, and new COI variants, especially for G. thymalli populations, are routinely discovered (Hansen et al. 2007). Therefore, the development of a simple, robust and relatively quick diagnostic test based on COI sequence discrimination is difficult. As such, the most robust and efficient approach to ensure rapid identification of $G$. salaris using currently available markers is to apply a rapid primary screen to identify all $G$. salaris/G. thymalli strains, followed by targeted COI sequencing to provide a more definitive identification. The objective of the current work was to enhance this initial screening process through the development of faster, more efficient molecular tests that are capable of dealing with high numbers of parasites.

Real-time PCR is used increasingly in diagnostic assays (Cavender et al. 2004, Corbeil et al. 2006, Snow et al. 2006, Jansson et al. 2008). It can offer higher sensitivity and, depending on the chemistry used, higher specificity through the use of a probe alongside the amplification primers. Although the actual real-time reaction is more costly than traditional PCR, this is offset by savings in subsequent costs and time, as post PCR processing steps are no longer required for detection of the PCR product and in some cases determination of the pathogen species, e.g. as when using RFLP. As such it is also very amenable to automation. Due to the last 2 factors, a real-time PCR assay for monitoring and detection of Gyrodactylus salaris/G. thymalli was considered a useful tool to develop, both for routine monitoring, and in particular in the event of a G. salaris outbreak where high parasite numbers may need to be processed.

\section{MATERIALS AND METHODS}

Rationale of approach. The objective of the current work was to develop a real-time PCR assay to replace ITS rDNA RFLP methodology in screening for potential Gyrodactylus salaris parasites. This should allow a significant reduction in time to obtain an initial diagnostic result. As with ITS/RFLP, the assay does not differentiate between G. salaris and G. thymalli.

Given that in some regions most or all specimens analysed may not be Gyrodactylus salaris/G. thymalli, we decided to develop additional assays for other commonly occurring Gyrodactylus species found on salmonids, viz. G. derjavinoides and G. truttae, and to use the 3 assays in a multiplex format. In this way, a positive result for $G$. derjavinoides or $G$. truttae would ensure that a negative G. salaris/G. thymalli result was not related to problems with the specimen such as DNA extraction, or with the G. salaris/G. thymalli assay. In addition, the specificity of the G. derjavinoides and $G$. truttae assays increase the overall robustness of the multiplex assay as opposed to running a generic Gyrodactylus assay, as a positive generic/negative G. salaris/G. thymalli result would not exclude the possibility that $G$. salaris was still present, but the specific assay not working. A generic assay for Gyrodactylus species was developed and tested alongside species-specific assays. A flow chart showing the proposed use of the real-time assay in Gyrodactylus diagnostics is given in Fig. 1.

Reference Gyrodactylus material for real-time PCR development: DNA extraction and species verification. G. salaris originating from the River Lærdalselva, Norway, were obtained from Dr. T. A. Mo (National Veterinary Institute Oslo). G. derjavinoides and G. truttae parasites were obtained from Scottish farmed and freshwater sites during routine sampling. DNA was released from parasites following tissue lysis in $10 \mu \mathrm{l}$ of lysis buffer, without further purification, as described in Cunningham et al. (2001), but substituting NP40 with its chemical equivalent IGEPAL ca-630 (Sigma). The Gyrodactylus specimens used to generate crude lysates were identified molecularly by PCR amplification of their ITS rDNA followed by RFLP analysis with the restriction enzyme HaeIII (Cunningham et al. 2001).

Testing for inhibition due to lysate in real-time PCR reactions. To determine if the parasite lysate caused inhibition of the real-time reaction, amplification of Taqman $^{\circledR}$ exogenous internal positive controls (IPCs; Applied Biosystems) was carried out in triplicate in the presence of undiluted and $10^{-1}$ - to $10^{-4}$-fold serial dilutions of Gyrodactylus salaris lysate. The reaction consisted of $1 \times$ TaqMan Universal PCR Master mix (with uracil N-glycosylase [UNG]; Applied Biosystems), 1× Exo IPC Mix (containing primers and probe for exoge- 


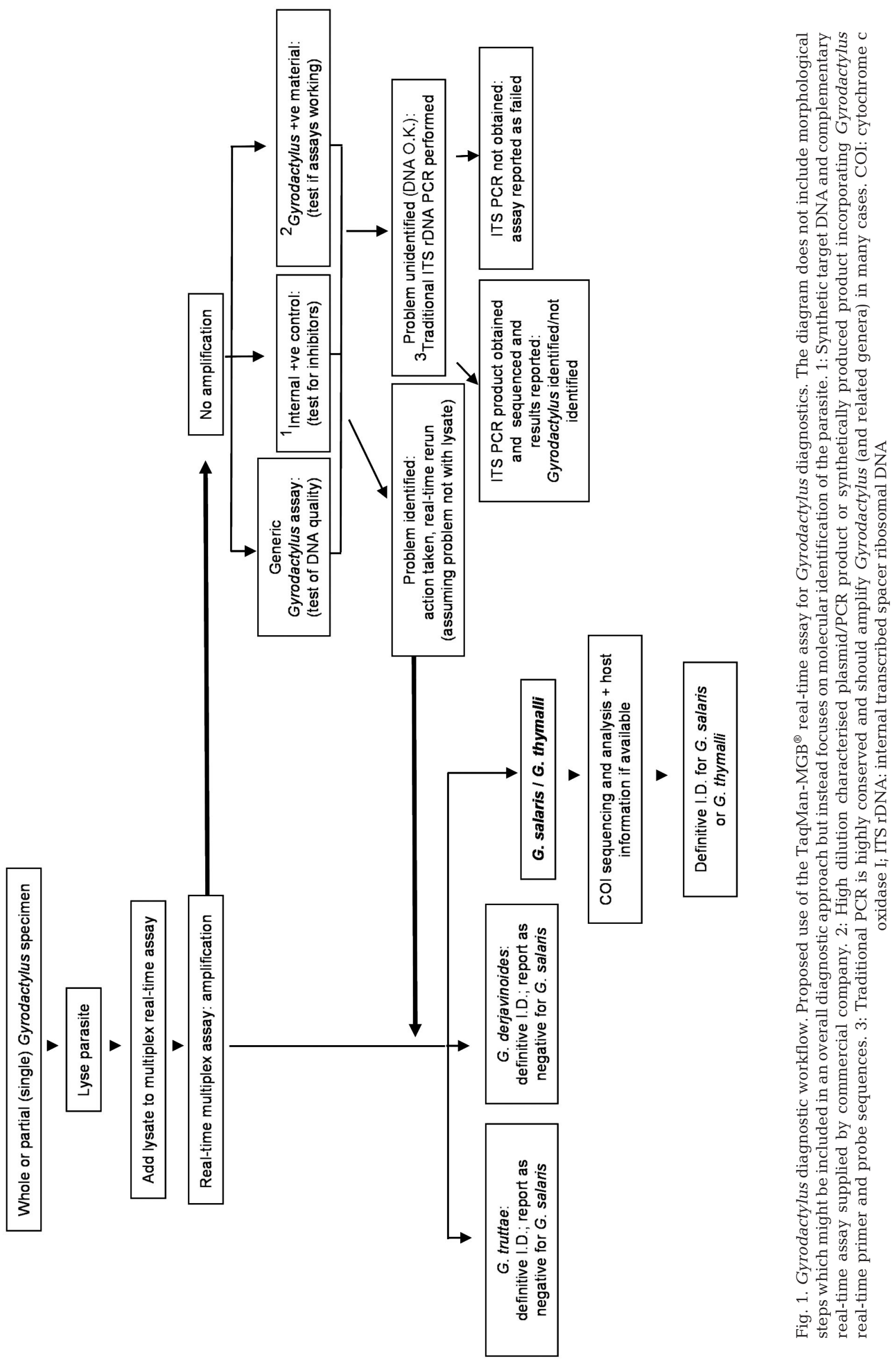


nous IPC amplification) and $1 \times$ Exo IPC DNA (Applied Biosystems) in addition to $1 \mu \mathrm{l}$ of G. salaris lysate or dilutions of lysate. Cycle threshold $(\mathrm{Ct})$ values for the IPCs in reactions containing G. salaris lysate were compared to 3 reactions without G. salaris lysate. In addition, undiluted and $10^{-1}$ - to $10^{-4}$-fold serial dilutions of the lysis buffer alone were added to IPC realtime PCR reactions in triplicate to determine if the buffer constituents rather than the Gyrodactylus tissue might be responsible for any observed inhibition. $\mathrm{Ct}$ values for IPC amplification in the presence of lysis buffer were compared to the IPC Ct values from reactions without lysis buffer. The Ct values were compared using Student's $t$-test.

Probe and primer design. ITS rDNA sequences from Gyrodactylus species belonging to the subgenus G. Limnonephrotus, G. wageneri group, which includes G. salaris and other commonly found salmonid parasites in European freshwaters such as G. derjavinoides, G. truttae and G. teuchis, as well as Gyrodactylus species belonging to other subgenera (Malmberg 1970, Ziętara et al. 2002, Matejusová et al. 2003), were downloaded from the public databases and aligned using CLUSTALW software (Thompson et al. 1994). TaqMan real-time PCR primers and probes were designed by eye, following recommended guidelines (Applied Biosystems) as far as possible, i.e. amplicon between 50 and 150 nucleotides in length, primers with a melting temperature $(\mathrm{Tm})$ between 58 and $60^{\circ} \mathrm{C},>2^{\circ} \mathrm{C}$ difference in $\mathrm{Tm}$ between primers, 20 to $80 \%$ GC content, maximum of $2 \mathrm{G} / \mathrm{C}$ 's in last 5 bases at $3^{\prime}$ end, probe; $10^{\circ} \mathrm{C}$ higher than primer $\mathrm{Tm}, 20$ to $80 \%$ GC content, no $\mathrm{G}$ at $5^{\prime}$ end, $<4$ contiguous G's, must have more C's than G's. Assays were designed for G. salaris, G. derjavinoides and G. truttae, choosing regions which showed interspecific variation in both primer and probe sequences, to increase specificity, but which were conserved intraspecifically. A generic assay for Gyrodactylus species was designed based on conserved sequences in the 5.8S rDNA of Gyrodactylus species from different subgenera. Primers and probes were used to search public databases for homologous sequences, using the megablast algorithm (Altschul et al. 1997) and parameters adjusted for short nucleotide sequences, to check their specificity for the target organisms. Oligo Analyzer (www.cmbn.no/ tonjum/biotools-free-software.html) was used to test for likelihood of primer/probe dimer formation. Primers and TaqMan ${ }^{\circledR}$ MGB (minor groove binding) probes (detailed in Table 1) were obtained from Invitrogen and Applied Biosystems (Applera), respectively.

Real-time PCR reactions: single target template. The multiplex real-time PCR consisted of 3 sets of primers and probes, targeting Gyrodactylus salaris/ G. thymalli, G. derjavinoides and G. truttae, respectively. The real- time PCR assay was performed on an ABI 7000 Sequence Detection System (Applied Biosystems). One microlitre of lysate (from a single species: G. salaris, G. derjavinoides, G. truttae, G. teuchis or G. lucii) was added to the following mix contained in individual wells of a 96-well optical plate (Applied Biosystems): 1× TaqMan Universal PCR Master mix (with UNG; Applied Biosystems), $0.9 \mu \mathrm{M}$ of each forward and reverse primer and $0.25 \mu \mathrm{M}$ of each probe and $\mathrm{dH}_{2} \mathrm{O}$ (Sigma) to a final volume of $20 \mu \mathrm{l}$. The cycling conditions were $50^{\circ} \mathrm{C}$ for $2 \mathrm{~min}, 95^{\circ} \mathrm{C}$ for $10 \mathrm{~min}$ followed by 35 cycles of $95^{\circ} \mathrm{C}$ for $15 \mathrm{~s}$ and $60^{\circ} \mathrm{C}$ for $1 \mathrm{~min}$. The threshold level was set at 0.2 , and the baseline was determined automatically by ABI 7000 software.

The real-time PCR assays for Gyrodactylus salaris/ G. thymalli, G. derjavinoides and G. truttae, which were used in the multiplex, were also run individually to test their efficiency as singleplexes. Reactions were as for multiplex reactions but containing primers and probe for single assays only. Cycling conditions were as for the multiplex reaction above.

The generic real-time assay for Gyrodactylus species was performed as described above for multiplex assays but using the genus-level forward and reverse primers, and TaqMan probe, and using $0.5 \mu \mathrm{l}$ of lysate. Cycling conditions were as for the multiplex assays above.

Assay efficiency and detection limits. The Gyrodactylus spp. crude lysates were diluted with $\mathrm{dH}_{2} \mathrm{O}$ (Sigma) in a 10 -fold series, ranging from $10^{-1}$ to $10^{-11}$. Real-time $\mathrm{PCR}$ reactions were performed in triplicate, as described above, for each dilution of parasite lysate (G. salaris, $G$. derjavinoides, G. truttae). Ct values for the reactions were plotted against- $\log _{10}$ dilution, and the slope $(\mathrm{m})$ of the regression line was calculated. The $\%$ amplification efficiency was calculated as $100 \times\left(10^{1 / m}-1\right)$ (Rutledge \& Cote 2003). An $m$ value of -3.3 represents $100 \%$ efficiency. Detection limits were determined based on the highest lysate dilution giving a positive result in all of its triplicate real-time reactions. Traditional ITS PCR and HaeIII RFLP was also performed in duplicate on each of the dilutions to compare its limit of detection to those obtained for real-time PCR. The ITS PCR and HaeIII digest were performed as described in Cunningham (1997) and Cunningham et al. (2001).

Specificity testing. The multiplex assay was tested against its individual target species (Gyrodactylus salaris/G. thymalli G. derjavinoides, G. truttae) and non-target species (G. teuchis, G. lucii) from widespread geographic areas. These specimens had previously been characterised using morphology, statistical classifiers and ITS rDNA RFLP as part of a comparative proficiency test of established diagnostic methods (Shinn et al. 2010) (Table 2). All specimens had been characterised by each method and the ITS rDNA and COI mtDNA sequenced from a number of them. 
Table 1. Primers and probes used in TaqMan-MGB ${ }^{\circledR}$ real-time PCR to identify Gyrodactylus species. F: forward; R: reverse

\begin{tabular}{|c|c|c|c|c|}
\hline Probe & Probe sequence $\left(5^{\prime}-3^{\prime}\right)$ & Primer sequence $\left(5^{\prime}-3^{\prime}\right)$ & $\begin{array}{l}\text { DNA strand } \\
\text { sequenced }\end{array}$ & $\begin{array}{l}\text { PCR product } \\
\text { size (bp) }\end{array}$ \\
\hline Gsal2 & FAM-TCTTATTAACCAGTTCTGC & $\begin{array}{l}\text { F: CGATCGTCACTCGGAATCG } \\
\text { R: GGTGGCGCACCTATTCTACA }\end{array}$ & Reverse & 60 \\
\hline Gder2 & VIC-CTGCTCAGAACTCATCTC & $\begin{array}{l}\text { F: TTGGTGCCCCATGATGGT } \\
\text { R: CGCACCTATTCAGCTAGTCTTAATACA }\end{array}$ & Reverse & 70 \\
\hline Gtrutt2 & NED-CCTTCGTTGTGCCCC & $\begin{array}{l}\text { F: TCGACGGACTCGATCGTTTC } \\
\text { R: CGCACCTGTTCTACTATAGACGAAGT }\end{array}$ & Reverse & 64 \\
\hline pGen & FAM-TTGCTGCACTCTTCATCG & $\begin{array}{l}\text { F: TGGATCACTCGGCTCACG } \\
\text { R: TGCGTTTCACATTGGTTAACACA }\end{array}$ & Reverse & 64 \\
\hline
\end{tabular}

The genus level assay was tested on a subset of the above samples including specimens from all species available.

Species level multiplex real-time PCR: multiple target template. The ability of the real-time multiplex assay to detect Gyrodactylus salaris in pooled lysates was determined using $1 \mu \mathrm{l}$ of template from a 1:10, 1:20 and 1:100 G. salaris: G. derjavinoides lysate mix, the parasites having been initially lysed individually in $10 \mu \mathrm{l}$ buffer as described previously.

\section{RESULTS}

\section{Testing for inhibition in real-time PCR reactions}

IPC amplification in reactions containing working concentration and serially diluted lysis buffer was not affected and did not differ significantly from IPC amplification in buffer-free controls. Addition of Gyrodactylus lysate also did not result in inhibition of IPC amplification. The average $\mathrm{Ct}$ value obtained for IPC amplification in a reaction mix without lysis buffer or Gyrodactylus lysate was $28.74 \pm 0.04$ (mean $\pm \mathrm{SE}, \mathrm{n}=$ $5)$. Average $\mathrm{Ct}$ values $(\mathrm{n}=3)$ for IPC amplification in the presence of a working concentration of lysis buffer or Gyrodactylus lysate, or in the presence of serial dilu- tions of these $\left(10^{-1}\right.$ - to $10^{-4}$-fold), ranged from 28.57 to 28.92 .

\section{Probe and primer design}

BLAST analysis showed that some of the speciesspecific primers or probes gave a $100 \%$ match to a number of unrelated organisms; however, the primers and probe combinations used in each assay only gave a $100 \%$ match for those species targeted by the assay.

The generic assay primer and probe sequences showed $100 \%$ homology to the $5.8 \mathrm{~S}$ rDNA of most Gyrodactylus species for which sequence data are available. A number of species, 16 in total, contained mismatches with the primers or probe nucleotide sequences. Of these, most mismatches could be accounted for by poor sequences, with only 3 species having reliably different nucleotides: G. poeciliae (AJ001844), G. rogatensis (AJ011411) and Gyrodactylus sp. (AY099508: from Rhynichthis osculus, Idaho, USA).

\section{Assay efficiency and detection limits}

The efficiencies of the multiplex and singleplex assays ranged from 93.1 to $100.5 \%$ and from 93.1 to $101.1 \%$, respectively (Table 3 ).

Table 2. Parasite specimens used in testing of Gyrodactylus spp. multiplex and generic real-time assays

\begin{tabular}{|c|c|c|c|}
\hline Parasite species & $\begin{array}{l}\text { No. of parasites tested with } \\
\text { multiplex assay (generic assay) }\end{array}$ & Host species & Country \\
\hline G. salaris/G. thymalli & $22(8)$ & $\begin{array}{c}\text { Salmo salar, Oncorhynchus mykiss, } \\
\text { Thymallus thymallus }\end{array}$ & $\begin{array}{l}\text { Norway }^{\mathrm{a}}, \text { Finland }^{\mathrm{a}} \text {, } \\
\text { Denmark }^{\mathrm{a}}, \text { England }^{\mathrm{b}}\end{array}$ \\
\hline G. derjavinoides & $100(27)$ & $\begin{array}{c}\text { S. salar, S. trutta, O. mykiss, } \\
\text { T. thymallus }\end{array}$ & $\begin{array}{l}\text { Scotland, England, } \\
\text { N. Ireland, Denmark, Italy }\end{array}$ \\
\hline G. truttae & $42(13)$ & S. trutta & N. Ireland, Scotland \\
\hline G. lucii & $9(11)$ & Esox lucius & England \\
\hline G. teuchis & $2(2)$ & O. mykiss & Italy \\
\hline
\end{tabular}


Detection limits for the real-time assays and for traditional ITS PCR/RFLP analysis on the same Gyrodactylus lysates and dilutions thereof are given in Table 3. The G. salaris/G. thymalli real-time assay in multiplex and singleplex format identified G. salaris at 10- to 100-fold higher dilutions compared to traditional PCR/RFLP. The G. derjavinoides and G. truttae realtime assays in multiplex format showed the same level of sensitivity as traditional PCR/RFLP in their ability to identify the parasites, whereas the assays in singleplex format identified parasites at 10-fold higher dilutions.

\section{Specificity testing}

The real-time multiplex assay identified all specimens of Gyrodactylus salaris/G. thymalli, G. derjavinoides and $G$. truttae correctly, with most $\mathrm{Ct}$ values ranging from 16.34 to 21.28 , and a single $G$. salaris specimen giving a $\mathrm{Ct}$ value of 27.15. As expected, the assay did not differentiate G. salaris from G. thymalli. The multiplex assay did not show amplification for the non-target species G. lucii and G. teuchis.

A subset of the specimens used for specificity testing above was used with the generic assay. The generic assay amplified all Gyrodactylus species, including those not amplified by the species-specific multiplex assay, with $\mathrm{Ct}$ values ranging from 16.11 to 20.52 .

\section{Species level multiplex real-time PCR: multiple target template}

The Ct values for 1:10, 1:20 and 1:100 lysate mixes of Gyrodactylus salaris: G. derjavinoides were $20.69 \pm$ $0.17: 17.78 \pm 0.12,22.14 \pm 0.12: 17.80 \pm 0.06$, and 24.39 $\pm 0.11: 17.60 \pm 0.03(n=3)$, respectively.

\section{DISCUSSION}

Generic and species-specific real-time assays for $G y-$ rodactylus parasites were developed during the current study. The generic assay was designed to amplify most members of the genus Gyrodactylus and successfully amplified all 6 species tested, although all were from the subgenus G. Limnonephrotus. The generic assay was designed against the ITS region (5.8S gene), as this represented the largest body of available sequence data. A small number of species showed nucleotide differences in their ITS rDNA when the assay's primer and probe sequences were compared to available sequences in the public database. More conserved regions may exist in the $18 \mathrm{~S}$ and $28 \mathrm{~S}$ rDNA, and these may be good targets for future generic assays. The generic assay can be used in conjunction with a species assay, or in a second PCR with specimens that had not amplified with species-specific assays, to help determine if negative results are due to a non-target species or to bad quality DNA or PCR inhibitors.

The multiplex real-time assay developed here identifies Gyrodactylus salaris/G. thymalli, G. derjavinoides and $G$. truttae. It does not distinguish $G$. salaris from the non-pathogenic G. thymalli, which currently requires COI sequence analysis to differentiate between them (although differences in the hard parts of the attachment organ can be used by experts in morphology). Based on the ITS rDNA region targeted, the G. salaris assay also does not differentiate between the Norwegian pathogenic strains and recently described G. salaris strains from Demark and Norway (Lindenstrøm et al. 2003, Jørgensen et al. 2007, Olstad et al. 2007, Robertsen et al. 2007), which show lower pathogenicity to salmon. These strains have a low number of nucleotide differences in their ITS rDNA, and some

Table 3. PCR efficiency and detection limits for real-time assays and traditional PCR used to identify Gyrodactylus species. $\%$ efficiency $=100 \times\left(10^{1 / m}-1\right)$, where $m=$ slope

\begin{tabular}{|c|c|c|c|c|c|c|c|}
\hline \multirow[t]{2}{*}{ Probe } & \multirow[t]{2}{*}{ Assay } & \multirow[t]{2}{*}{$\mathrm{R}^{2}$} & \multirow[t]{2}{*}{$y$-intercept } & \multirow[t]{2}{*}{ Slope } & \multirow{2}{*}{$\begin{array}{c}\text { PCR efficiency } \\
(\%)\end{array}$} & \multicolumn{2}{|c|}{ Limit of detection (dilution) } \\
\hline & & & & & & Real-time PCR & Traditional PCR/RFLP \\
\hline Gsal2 & Multiplex & 0.997 & 17.90 & 3.43 & 95.7 & $10^{-4}$ & $10^{-2}$ a \\
\hline Gder2 & Multiplex & 0.997 & 17.17 & 3.50 & 93.1 & $10^{-3}$ & $10^{-3}$ a \\
\hline Gtrutt2 & Multiplex & 0.989 & 18.35 & 3.31 & 100.5 & $10^{-3}$ & $10^{-3}$ a \\
\hline Gsal2 & Singleplex & 0.998 & 17.68 & 3.50 & 93.1 & $10^{-4}$ & $10^{-2} \mathrm{a}$ \\
\hline Gder2 & Singleplex & 0.998 & 18.06 & 3.37 & 98.1 & $10^{-4}$ & $10^{-3}$ a \\
\hline Gtrutt2 & Singleplex & 0.997 & 18.00 & 3.30 & 101.1 & $10^{-4}$ & $10^{-3}$ a \\
\hline Genus & Singleplex & $0.975^{\mathrm{b}}$ & $16.29^{\mathrm{b}}$ & $3.46^{\mathrm{b}}$ & $94.5(91.8 \text { to } 97.4)^{\mathrm{c}}$ & $10^{-6}$ to $10^{-7}$ & - \\
\hline
\end{tabular}


have been differentiated based on RFLP patterns (Lindenstrøm et al. 2003, Kania et al. 2007). In theory, realtime assays could be designed based on these few nucleotide differences. However, the stability of the 'non-pathogenic' state in these strains, and under different environmental conditions, has not been investigated and as such an assay which identifies all G. salaris strains is more desirable when monitoring for initial introductions of the parasite. Additional assays for specific identification of non-pathogenic strains may be useful in regions where G. salaris is endemic and different strains exist.

The Gyrodactylus salaris/G. thymalli real-time multiplex assay provided a 10-fold lower level of detection compared to traditional PCR, and this may improve diagnostics in some cases where specimen DNA is degraded. Lower detection limits also mean that low levels of contaminating G. salaris/G. thymalli DNA can be detected more easily. Using the multiplex format, it would be easier to distinguish contamination, as the $\mathrm{Ct}$ values obtained for the true species should be considerably lower than the contaminant in most cases.

The detection limits of the Gyrodactylus derjavinoides/G. truttae real-time assays in the multiplex format were the same as those for traditional PCR, while detection limits for the assays in singleplex format were 10-fold lower, indicating that there may be some interaction between multiplexed primers and probes which reduces the individual efficiencies.

With respect to identification of individual Gyrodactylus parasites, higher detection limits are not as important an issue as for single-celled organisms such as viruses, bacteria or protozoa, since it involves the identification of a parasite known to be already present rather than detection of potentially low numbers of 'unseen' microscopic organisms.

In certain situations it may be desirable to pool Gyrodactylus DNA, as this would allow more parasites to be analysed per real-time plate, thereby reducing time and cost of screening. With respect to pooled parasites, G. salaris was detectable well within the 35 cycles used when diluted 1:10 to 1:100 with G. derjavinoides DNA. Currently, sequencing of the COI mtDNA is required to confirm a positive $G$. salaris result, as both the ITS RFLP and the real-time assay developed here do not differentiate G. salaris from G. thymalli. Although it appears to preferentially amplify G. salaris/G. thymalli DNA, the COI PCR (Hansen et al. 2003) has not been checked extensively against other parasites to test for specificity. In addition, the sensitivity of the COI PCR has not been tested. Pooling parasites prior to lysis, though faster for initial analysis, might result in delays obtaining subsequent sequence data for G. salaris/ G. thymalli if present in the pool. Therefore, the proposed approach for analysing pooled samples is to maintain the lysates separately and pool aliquots of these, at least until such time as the specificity and sensitivity of the COI PCR has been verified.

If parasites were pooled before lysing, then depending on the final lysate volume, higher DNA concentrations for certain species might reduce detection limits for species in lower numbers, so the real-time assay would have to be re-evaluated for this approach.

The real benefit of the real-time PCR presented here is in the reduction in time to obtain a preliminary diagnosis, and the reduced time required of staff, the latter compensating for the higher reagent costs (which are variable, depending on supplier used and how many parasites are processed together). Compared to ITS PCR followed by RFLP and associated gel electrophoresis, the real-time PCR represents a single reaction with real-time provision of results. Once the parasites have been lysed to release DNA, identification can currently be obtained in approximately $80 \mathrm{~min}$ using the real-time assay as opposed to approximately 350 min (allowing 90 min for RFLP digestion) using ITS PCR/RFLP analysis (Cunningham 1997). The quoted times are for running of the reactions/gels only and do not include preparation time, which again would be considerably more for the ITSPCR/RFLP due to the additional steps in the methodology.

In summary, the species-specific real-time PCR presented here does not improve on the specificity of current molecular diagnostics in that it does not differentiate between Gyrodactylus salaris and G. thymalli. However, it allows quicker processing of samples and identification of potential G. salaris specimens, and as such represents a valuable tool in monitoring programmes for $G$. salaris. This is especially true for situations where large numbers of parasites require testing, such as following an outbreak or screening parasites to prove the absence of G. salaris after attempted eradication. Diagnostic labs are increasingly moving to real-time technology, and a real-time assay for G. salaris will allow Gyrodactylus cases to be run side by side with other pathogens on the same plate where space allows, again decreasing overall staff time. The realtime assay developed here is currently being used for Gyrodactylus identification at the Marine Laboratory, Marine Scotland, Aberdeen.

Acknowledgements. We thank N. Bain, Marine Scotland, Marine Laboratory Aberdeen, for advice on validation of the assay, T. A. Mo, National Veterinary Institute, Oslo, for provision of G. salaris material used in initial testing of assays, K. Buchmann, University of Copenhagen, A. Shinn and B. Paladini, Institute of Aquaculture, Stirling, A. Duguid, Scottish Environmental Protection Agency, M. Longshaw, Centre for Environment, Fisheries and Aquaculture Science, and D. Graham, AgriFood and Biosciences Institute, for provision of specimens used in validation. The work was funded by the Scottish Government Marine Directorate, under ROAME FC11104. 


\section{LITERATURE CITED}

Altschul SF, Madden TL, Schäffer AA, Zhang J, Zhang Z, Miller W, Lipman DJ (1997) Gapped BLAST and PSIBLAST: a new generation of protein database search programs. Nucleic Acids Res 25:3389-3402

Bakke TA, Harris PD, Cable J (2002) Host specificity dynamics: observations on gyrodactylid monogeneans. Int $\mathrm{J}$ Parasitol 32:281-308

Cable J, Harris PD (2002) Gyrodactylid developmental biology: historical review, current status and future trends. Int J Parasitol 32:255-280

Cavender WP, Wood JS, Powell MS, Overturf K, Cain KD (2004) Real-time quantitative polymerase chain reaction (QPCR) to identify Myxobolus cerebralis in rainbow trout Oncorhynchus mykiss. Dis Aquat Org 60:205-213

Corbeil S, Arzul I, Diggles B, Heasman M, Chollet B, Berthe FC, Crane MS (2006) Development of a TaqMan PCR assay for the detection of Bonamia species. Dis Aquat Org $71: 75-80$

Council of the European Union (2006) Council Directive 2006/ 88/EC: on animal health requirements for aquaculture animals and products thereof, and on the prevention and control of certain diseases in aquatic animals. European Commission, Brussels

Cunningham CO (1997) Species variation within the internal transcribed spacer (ITS) region of Gyrodactylus (Monogenea: Gyrodactylidae) ribosomal RNA genes. J Parasitol 83:215-219

> Cunningham CO, Mo TA, Collins CM, Buchmann K, Thiery R, Blanc G, Lautraite A (2001) Redescription of Gyrodactylus teuchis Lautraite, Blanc, Thiery, Daniel \& Vigneulle, 1999 (Monogenea: Gyrodactylidae); a species identified by ribosomal RNA sequence. Syst Parasitol 48:141-150

> Hansen H, Bachmann L, Bakke TA (2003) Mitochondrial DNA variation of Gyrodactylus spp. (Monogenea, Gyrodactylidae) populations infecting Atlantic salmon, grayling, and rainbow trout in Norway and Sweden. Int J Parasitol 33:1471-1478

Hansen H, Martinsen L, Bakke TA, Bachmann L (2006) The incongruence of nuclear and mitochondrial DNA variation supports conspecificity of the monogenean parasites Gyrodactylus salaris and G. thymalli. Parasitology 133: 639-650

Hansen H, Bakke TA, Bachmann L (2007) Mitochondrial haplotype diversity of Gyrodactylus thymalli (Platyhelminthes; Monogenea): extended geographic sampling in United Kingdom, Poland, and Norway reveals further lineages. Parasitol Res 100:1389-1394

Jansen PA, Bakke TA (1991) Temperature dependent reproduction and survival of Gyrodactylus salaris Malmberg, 1957 (Platyhelminthes: Monogenea) on Atlantic salmon (Salmo salar L.). Parasitology 102:105-112

Jansson E, Lindberg L, Saker E, Aspan A (2008) Diagnosis of bacterial kidney disease by detection of Renibacterium salmoninarum by real-time PCR. J Fish Dis 31:755-763

Johnsen BO, Møkkelgjerd PI, Jensen AJ (1999) The parasite Gyrodactylus salaris on salmon parr in Norwegian rivers, status report at the beginning of year 2000. NINA Oppdargsmelding 617:1-129 (in Norwegian, with English summary)

Jørgensen TR, Larsen TB, Jørgensen LG, Bresciani J, Kania PW, Buchmann K (2007) Characterisation of a low pathogenic form of Gyrodactylus salaris from rainbow trout. Dis Aquat Org 73:235-244
Kania PW, Jørgensen TR, Buchmann K (2007) Differentiation between a pathogenic and a non-pathogenic form of Gyrodactylus salaris using PCR-RFLP. J Fish Dis 30: 123-126

Kuusela J, Ziętara MS, Lumme J (2007) Hybrid origin of Baltic salmon-specific parasite Gyrodactylus salaris: a model for speciation by host switch for hemiclonal organisms. Mol Ecol 16:5234-5245

> Lindenstrøm T, Collins CM, Bresciani J, Cunningham CO, Buchman K (2003) Characterisation of a Gyrodactylus salaris variant: infection biology, morphology and molecular genetics. Parasitology 127:165-178

Malmberg G (1970) The excretory systems and the marginal hooks as a basis for the systematics of Gyrodactylus (Trematoda, Monogenea). Ark Zool 23:1-237

> Malmberg G (1993) Gyrodactylidae and gyrodactylosis of Salmonidae. Bull Fr Peche Piscic 328:5-46

> Matejusová I, Gelnar M, Verneau O, Cunningham CO, Littlewood DTJ (2003) Molecular phylogenetic analysis of the genus Gyrodactylus (Platyhelminthes: Monogenea) inferred from rDNA ITS region: subgenera versus species groups. Parasitology 127:603-611

Meinilä M, Kuusela J, Zítara MS, Lumme J (2004) Initial steps of speciation by geographic isolation and host switch in salmonid pathogen Gyrodactylus salaris (Monogenea: Gyrodactylidae). Int J Parasitol 34:515-526

> Olstad K, Robertsen G, Bachmann L, Bakke TA (2007) Variation in host preference within Gyrodactylus salaris (Monogenea): an experimental approach. Parasitology 134: $589-597$

Peeler E, Thrush M, Paisley L, Rodgers C (2006) An assessment of the risk of spreading the fish parasite Gyrodactylus salaris to uninfected territories in the European Union with the movement of live Atlantic salmon (Salmo salar) from coastal waters. Aquaculture 258:187-197

> Robertsen G, Hansen H, Bachmann L, Bakke TA (2007) Arctic charr (Salvelinus alpinus) is a suitable host for Gyrodactylus salaris (Monogenea, Gyrodactylidae) in Norway. Parasitology 134:257-267

Rutledge RG, Cote C (2003) Mathematics of quantitative kinetic PCR and the application of standard curves. Nucleic Acids Res 31:e93

Shinn AP, Collins C, Garcia-Vásquez A, Snow M and others (2010) Multi-centre testing and validation of current protocols for Gyrodyctylus salaris (Monogenea) identification. $\mathrm{J}$ Parasitol (in press)

Snow M, McKay P, McBeath AJ, Black J and others (2006) Development, application and validation of a TaqMan real-time RT-PCR assay for the detection of infectious salmon anaemia virus (ISAV) in Atlantic salmon (Salmo salar). Dev Biol 126:133-145

> Sterud E, Mo TA, Collins CM, Cunningham CO (2002) The use of host specificity, pathogenicity, and molecular markers to differentiate between Gyrodactylus salaris Malmberg, 1957 and G. thymalli Zitnan, 1960 (Monogenea: Gyrodactylidae). Parasitology 124:203-213

> Thompson JD, Higgins DG, Gibson TJ (1994) CLUSTAL W: improving the sensitivity of progressive multiple sequence alignment through sequence weighting, position-specific gap penalties and weight matrix choice. Nucleic Acids Res 22:4673-4680

Ziętara MS, Huyse T, Lumme J, Volckaert FA (2002) Deep divergence among subgenera of Gyrodactylus inferred from rDNA ITS region. Parasitology 124:39-52 